\title{
Novas espécies de Myrsine L. (Myrsinaceae) Para o BrasiL ${ }^{1}$
}

\author{
Maria de Fátima Freitas² \& Luiza Sumiko Kinoshita ${ }^{3}$
}

\begin{abstract}
Resumo
(Novas espécies de Myrsine L. (Myrsinaceae) para o Brasil) São descritas e ilustradas três novas espécies de Myrsine: Myrsine altomontana M. F. Freitas \& L. S. Kinoshita, M. cipoensis M. F. Freitas \& L. S. Kinoshita e M. rubra M. F. Freitas \& L. S. Kinoshita.
\end{abstract}

Palavras-chave: Myrsinaceae, Myrsine, taxonomia, Brasil.

\section{Abstract}

(New species of Myrsine L. (Myrsinaceae) from Brazil) Three new species of Myrsine are described and illustrated: Myrsine altomontana M. F. Freitas \& L. S. Kinoshita, M. cipoensis M. F. Freitas \& L. S. Kinoshita and M. rubra M. F. Freitas \& L. S. Kinoshita.

Key-words: Myrsinaceae, Myrsine, taxonomy, Brazil.

\section{INTRODUÇão}

Myrsine (incluindo Rapanea) é um gênero pantropical com cerca de 34 espécies no Brasil (Mez, 1902). O conhecimento das espécies brasileiras de Myrsinaceae é escasso, e a única obra, anterior a de Mez (1902), com todos os gêneros ocorrentes na flora brasileira foi publicada por Miquel (1856) e, posteriormente, Edwal (1905) com espécies para a flora paulista, porém sem novidades. Após um longo período, os estudos com as espécies brasileiras de Myrsine foram realizados em floras regionais ou locais: Smith \& Downs (1957); Jung (1981); Siqueira (1987, 1993); Jung-Mendaçolli \& Bernacci (1997a, 2001); Konno \& Ferreira (2001); Fiaschi et al. (2004); Jung-Mendaçolli et al. (2005), uma espécie nova publicada por Jung-Mendaçolli \& Bernacci (1997b) e poucos tratamentos taxonômicos (Freitas 2003; Freitas \& Kinoshita 2004).

O presente trabalho é parte dos resultados das investigações das autoras com espécies brasileiras e são apresentadas as descrições de três novas espécies de Myrsine. Considera-se a circunscrição do gênero Myrsine adotada por Fosberg \& Sachet (1975, 1980) e Pipoly (1997), discutida por Freitas (2003).
1. Myrsine altomontana M. F. Freitas \& L. S. Kinoshita, sp. nov.

Tipo: BRASIL. PARANÁ: Quatro Barras, Morro Sete, 1200 m.s.m., 6.VI.1989, fl., O.S. Ribas et al. 120 (holótipo MBM; isótipo RB).

Figura $1 \mathrm{a}-\mathrm{g}$

Proxime affinis et altitude Myrsine gardnerianae A. DC. simillima, quae differt foliis ovalibus vel ellipticis, parvis, apice acuto-acuminato et floribus masculis cum appendicibus alternis in tubo stamineo insertis.

Arbusto $(0,6) 1-2(3) \mathrm{m}$ alt., ramos terminais 1-2 mm diam., glabros. Folhas 2,5$3,5 \times 1-1,5 \mathrm{~cm}$, cartáceas a coriáceas, glabras, ovadas ou elípticas, ápice agudo a acuminado, base aguda, margem inteira, levemente revoluta, nervura principal proeminente em ambas as faces, na face abaxial com $0,8 \mathrm{~mm}$ larg. na base foliar, folhas jovens com linhas translúcidas, nervuras secundárias evidentes apenas no material seco; pecíolo alvoesverdeado, (2)3-5(8) mm compr. Inflorescências com pedúnculo curto, 0,5-1 mm compr., 5-8 flores; bractéolas $1 \mathrm{~mm}$ compr., triangulares, tricomas curtos. Flores pentâmeras, 3-4 $\mathrm{mm}$ compr.; pedicelos 0,8-1 mm compr.; sépalas $0,5-1 \mathrm{~mm}$ compr., triangulares, tricomas curtos, esparsos e raros, cavidades secretoras

\footnotetext{
Artigo recebido em03/2005. Aceito para publicação em 07/2005.

${ }^{1}$ Parte da tese de doutorado da primeira autora. Unicamp, Depto. Botânica. Apoio CNPq.

${ }^{2}$ Instituto de Pesquisas Jardim Botânico do Rio de Janeiro, Rua Pacheco Leão 915, 22460-030, Rio de Janeiro, Brasil; fatima.freitas@jbrj.gov.br

${ }^{3}$ Unicamp, Depto. Botânica, Caixa Postal 6109, Campinas, São Paulo, Brasil. luizakin@unicamp.br
} 
globosas; pétalas lanceoladas, 1,8-2 x $1 \mathrm{~mm}$, cavidades secretoras elípticas e lineares em maior densidade que as globosas; estames 1-1,2 mm compr., estaminódios $0,8-1 \mathrm{~mm}$ compr., filetes conatos, adnatos às pétalas, apêndices alternos aos filetes no tubo estaminal presentes; ovário e pistilódio globosos, ca. 1 x $1 \mathrm{~mm}$; estigma ca. $0,5 \mathrm{~mm}$. Fruto globoso, 3-4 $\mathrm{X} 2,5-3 \mathrm{~mm}$, pericarpo do fruto imaturo verde, com muitas cavidades internas e secreção escura.

Parátipos: BRASIL. PARANÁ: Campina Grande do Sul, Pico Caratuva, 1950 m.s.m, 5.X.1967, fl., G. Hatschbach 17315 (MBM); Serra Capivari Grande, 1500 m.s.m, 8.II.1971, fl., G. Hatschbach 26314 (MBM); Guaraqueçaba, Rio Pardinho, Serra da Virgem Maria, fl., 3.VII.1987, Y.S. Kuniyoshi et al. 5207 (MBM); Guaratuba, Serra de Araçatuba, 19.VI.1960, fl., G. Hatschbach 6681 (MBM); 26.VII.1997, fr., O. S. Ribas et al. 1930 (MBM); Quatro Barras, Morro Mãe Catira, 14.V.1987, fl., R. Kummrow et al. 2909 (MBM, MO); SANTA CATARINA: São Joaquim, Serra do Oratório, IV.1967, fr., $J$. Mattos 14574 (HAS, RB, UEC). SÃO PAULO: Cananéia, Ilha do Cardoso, Pico do Cardoso, ca. 840 m.s.m., 5.XII.1990, fr., F. Barros et al. 2078 (IAC, SP); 9.IV.1991, fr., F. Barros et al. 2245 (IAC, SP).

Myrsine altomontana ocorre geralmente em florestas associadas a campos de altitude, nos estados do Paraná e Santa Catarina, também registrada no Pico do Cardoso, extremo sul do litoral do estado de São Paulo. Nos herbários catarinenses é encontrada, muitas vezes, sob a determinação de $M$. wettsteinii (Mez) Otegui, em virtude da utilização do trabalho de Smith \& Downs (1957) para a identificação dos materiais coletados nesta região. Esta espécie é considerada por Freitas (2003) um sinônimo de $M$. gardneriana A.DC. Myrsine altomontana ocorre em altitudes elevadas, ambiente onde também ocorre $M$. gardneriana, porém suas folhas são ovadas com ápice agudo a acuminado, e com apêndices alternos aos filetes nas flores masculinas, e diferencia-se da segundaque são plantas mais robustas, com folhas mais amplas e lanceoladas, e sem os apêndices alternos aos filetes.

2. Myrsine cipoensis M. F. Freitas \& L. S. Kinoshita, sp. nov.

Tipo: BRASIL. MINAS GERAIS: Santana do Riacho, Serra do Cipó, km 125 da Rodovia Belo Horizonte - Conceição do Mato Dentro, Córrego da Cachoeirinha, ao lado da estátua do Velho Juca, 7.XII.1991, fl., J. R. Pirani et al. CFSC 12822 (holótipo SPF; isótipo RB).

Figura $1 \mathrm{~h}-\mathrm{m}$

Species nova habitu suffruticoso et foliis congestis Myrsine squarrosae (Mez) M. F. Freitas \& L. S. Kinoshita affinis sed foliis sessilibus, ovatis, ellipticus, acutis, limbo cum secretione fusca, floribus minoribus et subsessilibus differt.

Arbusto $0,7 \mathrm{~m}$ alt., ramos terminais ca. 2 mm diâm., glabros, contorcidos, entrenó curto, 2-3 mm compr. Folhas sésseis, 2-4 x 1,3-1,5 $\mathrm{cm}$, coriáceas, congestas no ápice, glabras, lisas, ovadas a elípticas, ápice agudo, base arredondada, revoluta, margem inteira, levemente revoluta, nervura principal proeminente em ambas as faces, na face abaxial com $1 \mathrm{~mm}$ larg. na base foliar, cavidades secretoras com conteúdo escuro, evidentes em folhas jovens e adultas, nervuras secundárias evidentes no material seco. Inflorescências com pedúnculo ca. $1 \mathrm{~mm}$ compr., 4-5 flores, bractéolas ca. $1 \mathrm{~mm}$ compr., triangulares, tricomas curtos. Flores femininas pentâmeras, 2,5-3 $\mathrm{mm}$ compr.; pedicelos 0,3-0,5 mm compr.; sépalas ca. $1 \mathrm{~mm}$ compr., triangulares, tricomas curtos, esparsos e raros, cavidades secretoras globosas; pétalas ovado-lanceoladas, 1,5-2 x $1 \mathrm{~mm}$, cavidades secretoras globosas, numerosas até a base da corola; estaminódios 0,8-1 mm compr., filetes conatos, apêndices alternos aos filetes no tubo estaminal ausentes; ovário globoso 1 x $1 \mathrm{~mm}$; estigma ca. $1 \mathrm{~mm}$. Flores masculinas e frutos não vistos. 


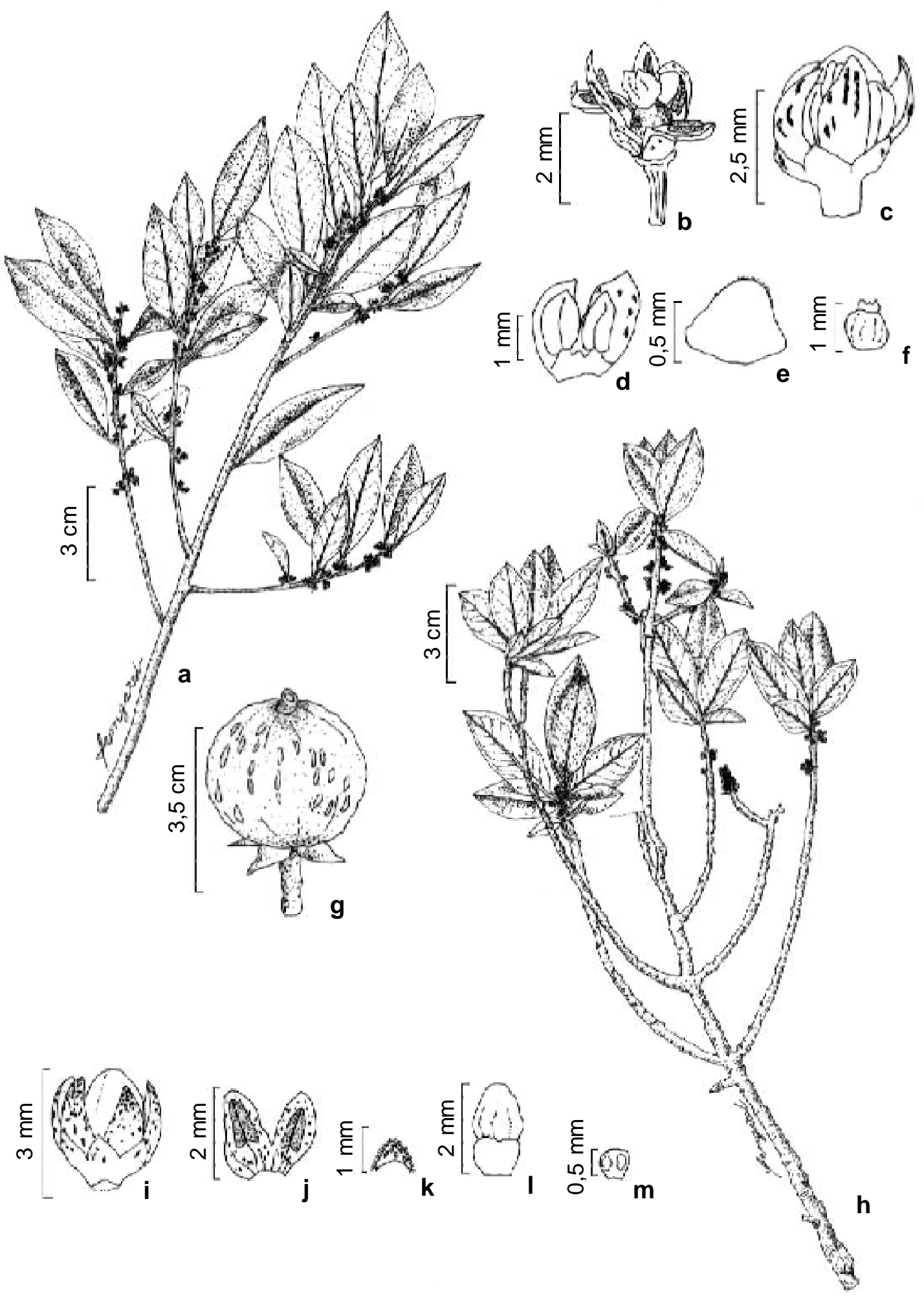

Figura 1 - a-g: Myrsine altomontana M. F. Freitas \& L. S. Kinoshita. a - ramo florífero; b - flor feminina; c - flor masculina; d - detalhe da inserção dos estames com apêndice alterno; e - bractéola; f - pistilódio; g - fruto. h-m: Myrsine cipoensis M. F. Freitas \& L. S. Kinoshita. h - ramo florífero; i - flor feminina; j detalhe da inserção dos estaminódios; k - bractéola; 1 - ovário e estigma; m - placenta. (a, c-f: Ribas 120; b: Kummrow 2909; g: Ribas 1930; h-m:Pirani CFSC 12822). 
Esta espécie caracteriza-se, principalmente, por ser um arbusto pequeno, com ramos contorcidos e lenhosos, entrenó curto, folhas congestas no ápice e flores subsésseis. É diferenciada de M. squarrosa (Mez) M. F. Freitas \& L. S. Kinoshita pelas folhas e flores com dimensões bem menores, folhas ovadas, sésseis, de ápice agudo, nervuras bem marcadas e cavidades secretoras com conteúdo muito evidente, tanto em folhas jovens como adultas. Sendo conhecido apenas o material tipo, esta espécie pode ser considerada rara e endêmica da Serra do Cipó. Em visita a localidade de ocorrência não foi possível encontrá-la.

3. Myrsine rubra M. F. Freitas \& L. S. Kinoshita, sp. nov.

Tipo: BRASIL. PARANÁ: Paranaguá, Ilha Rasa da Cotia, 3.IV.1987, (fr.), Y. S. Kuniyoshi \& Fr. Galvão 5563 (holótipo MBM).

Figura 2 a-h

Species nova habitu Myrsine umbellatae Mart. affinis, sed recedit cortice interno rubro, foliis lanceolatis, ovatis, ellipticus, acuto-acuminatis, petalis lanceolatis ca. $2 \mathrm{~mm}$ longis et fructibus ellipticis 6-7 mm longis.

Árvore de 4-10 m alt., ramos terminais ca. 2 mm diâm., glabros. Folhas 8-10 x 2-3 $\mathrm{cm}$, cartáceas, glabras, lisas, lanceoladas, ovadas, elípticas, ápice agudo a acuminado, base aguda, revoluta, margem inteira, levemente revoluta, nervura mediana proeminente em ambas as faces, na face abaxial com 1,5 $\mathrm{mm}$ larg. na base foliar, glândulas evidentes, cavidades secretoras lineares raras e evidentes em folhas jovens, nervuras secundárias não evidentes; pecíolo 0,5-0,8 mm compr. Inflorescências com pedúnculo curto, 1-2 mm compr., 6-12 flores; bractéolas $0,5 \mathrm{~mm}$ compr., triangulares, tricomas curtos; flores pentâmeras, 3-4 mm compr.; pedicelos 0,5-1 mm compr.; sépalas 0,8-1 mm compr., ovadas, tricomas curtos, esparsos, cavidades secretoras globosas; pétalas lanceoladas, $2 \times 1 \mathrm{~mm}$, cavidades secretoras globosas esparsas; anteras da flor masculina ca. $1 \mathrm{~mm}$ compr., pistilódios cônicos, ca. $1 \mathrm{~mm}$ compr.; estaminódios da flor feminina ca. $1 \mathrm{~mm}$ compr., apêndices alternos aos filetes no tubo estaminal ausentes; ovário elipsóide, ca. 1 x $1 \mathrm{~mm}$; estigma ca. $1,5 \mathrm{~mm}$. Fruto elipsóide, 6-7 x 2,5-3 mm.

Parátipos: BRASIL. ESPÍRITO SANTO: Linhares, Reserva Florestal de Linhares, estrada da Bomba d'Agua, no final da estrada, 15.VI.1989, fl., D. A. Folli 929 (CVRD, RB). PARANÁ: Paranaguá, Vila Balneária, 24.VII.1947, fl., G. Hatschbach 757 (MBM, RB); Olho d'Água, 9.VIII.1977, fl., $G$. Hatschbach 40161 (MBM). RIO DE JANEIRO: Angra dos Reis, Vila Velha, Ponta da Figueira, 2.XI.1986, fr., M. Gomes et al. 67 (RB); Macaé, entre lagoa Comprida e Carapebus, 18.IX.1986, fl., D. Araújo et al. 7591 (GUA, RB).

Esta espécie é diferenciada de $M$. umbellata Mart. que apresenta folhas maiores e mais largas, inflorescências com muitas flores, pedicelos florais com ca. $8 \mathrm{~mm}$ compr. que, de um modo geral, é um caráter muito importante na identificação de espécies de Myrsine, e frutos globosos. Myrsine rubra apresenta inflorescências com poucas flores, pedicelos florais reduzidos e frutos elipsóides. A casca interna vermelha de $M$. rubra é mantida após a herborização, e verificada na região do corte dos ramos.

Foi observada uma grande população em áreas de várzea da Reserva Florestal de Linhares, Espírito Santo. Nesta localidade a espécie é conhecida como "zezão" em homenagem a um funcionário da Reserva. No estado do Paraná é popularmente conhecida como "capororocão", denominação muito comum às espécies de Myrsinaceae. Ocorre do Espírito Santo ao sul do Paraná, próximo a ambientes alagados em vegetação de restinga. Em coleções de herbário é encontrada, muitas vezes, sob a identificação errônea de $M$. umbellata. 


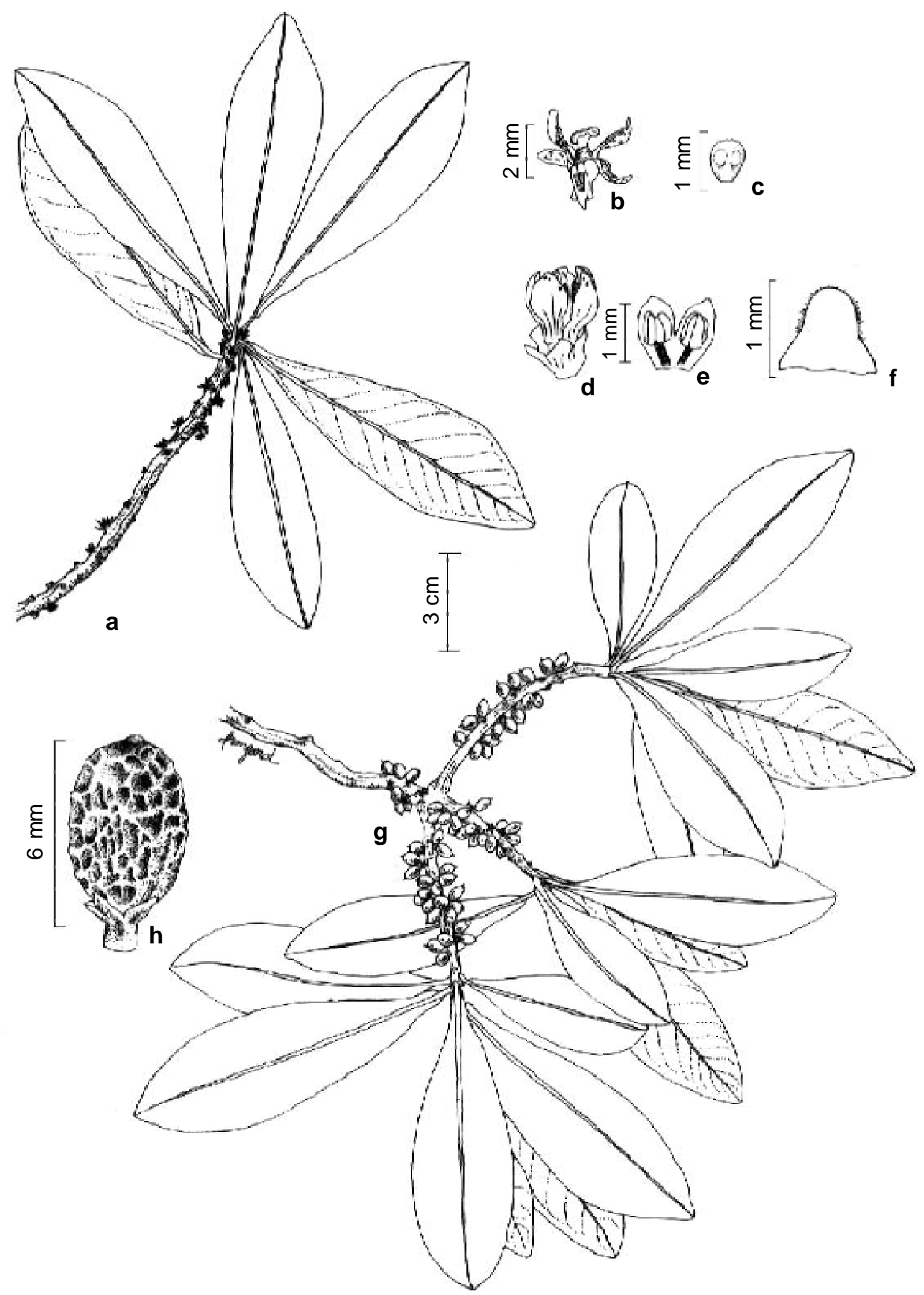

Figura 2 - Myrsine rubra M. F. Freitas \& L. S. Kinoshita. a - ramo florífero; b - flor feminina; c - placenta; d - flor masculina; e - detalhe da inserção dos estames; f - bractéola; g - ramo frutífero; h - fruto (a-c: Hatschbach 40161; d-f: Folli 929; g-h: Kuniyoshi \& Fr. Galvão 5563).

Rodriguésia 56 (87): 67-72. 2005 


\section{Agradecimentos}

Ao CNPq pela bolsa de doutorado concedida à primeira autora; ao Departamento de Botânica da Unicamp e ao Instituto de Pesquisas Jardim Botânico do Rio de Janeiro, pelas condições oferecidas para realização deste trabalho; aos curadores dos herbários visitados e pelo empréstimo dos materiais, ao Dr. Jorge Fontella Pereira pela tradução em latim; ao Dr. André Marcio Araújo Amorim pelas sugestões no texto e à Irmgard Schanner pela confecção das ilustrações.

\section{REFERÊNCIAS BIBLIOG RÁFICAS}

Edwall, G. 1905. Família Myrsinaceae. In Flora Paulista. Comissão Geographica e Geológica de São Paulo 15: 1-45.

Fiaschi, P.; Lobão, A. Q. \& Christiano, J. C. S. 2004. Flora de Grão-Mogol, Minas Gerais: Myrsinaceae. Boletim de Botânica da Universidade de São Paulo 22(2): 319-322.

Fosberg, R. R. \& Sachet, M. 1975. Polynesian plant studies. 1-5. Smithsonian Contributions to Botany 21: 1-25.

1980. Sytematics studies of Mycronesian plants. Smithsonian Contributions to Botany 45: 1-40.

Freitas, M. F. 2003. Estudos taxonômicos em espécies de Myrsine (Myrsinaceae) das regiões sudeste e sul do Brasil. Tese de Doutorado, Unicamp, Campinas, SP.

Freitas, M. F. \& Kinoshita, L. S. 2004. New combinations of Brazilian Myrsine (Myrsinaceae). Bradea 10(1): 1-7.

Jung, S. L. 1981. Flora fanerogâmica da Reserva do Parque Estadual das Fontes do Ipiranga (São Paulo, Brasil): 74Myrsinaceae. Hoehnea 9: 88-91.

Jung-Mendaçolli, S. L. \& Bernacci, L. C. 1997a. Flora fanerogâmica da Ilha do Cardoso (SP, Brasil): Myrsinaceae. In: Melo, M. M. R. F., Barros, F., Chiea, S. A. C., Kirizawa, M., Jung-Mendaçolli, S. L. \& Wanderley, M. G. L. Flora fanerogâmica da Ilha do Cardoso. São Paulo, v. 5, p. 8198. 1997b. Rapanea hermogenesii

Jung-Mendaçolli \& Bernacci sp. n. (Myrsinaceae): uma nova espécie da Mata Atlântica (Brasil). Boletim de Botânica da Universidade de São Paulo 16: 31-35. 2001. Myrsinaceae da APA de Cairuçú, Parati (Rio de Janeiro, Brasil). Rodriguésia 52(81): 49-64.

Jung-Mendaçolli, S. L., Bernacci, L. C.\& Freitas, M. F. 2005. Myrsinaceae. In: Wanderley, M. G. L.; Shepherd, G. J.; Melhem, T. S. \& Giulietti, A. M. Flora fanerogâmica do estado de São Paulo. São Paulo. 4: 279-300.

Konno, T. U. P. \& Ferreira, T. C. N. 2001. Myrsinaceae. In: Costa, A. F. \& Dias, I. C. A. Flora do Parque Nacional da Restinga de Jurubatiba e arredores, Rio de Janeiro, Brasil: listagem, florística e fitogeografia. Angiospermas - Pteridófitas - Algas continentais. Ser. Livros 8. Museu Nacional, Universidade Federal do Rio de Janeiro, p. 99-100.

Mez, C. 1902. Myrsinaceae. In: Engler, H. G. A. Das Pflanzenreich. Berlin, Wilhelm Engelmann, 9(4): 1-437.

Miquel, F. A. G. 1856. Myrsineae. In: Martius, C. F. P., Eichler, A. G. \& Urban, I. (eds.) Florabrasiliensis. Munchen, Wien, Leipzig, 10: 269-338, est. 24-59.

Pipoly, J. J. 1996. Contributions toward a new flora of the Philippines: I. A synopsis of the genus Myrsine (Myrsinaceae). Sida 17(1): 115-162.

Siqueira, J. C. 1987. Considerações taxonômicas sobre as espécies do gênero Rapanea Aublet (Myrsinaceae) ocorrentes no Rio Grande do Sul. Pesquisas Botânica 38: 147-156.

1993. O gênero Rapanea Aublet (Myrsinaceae) na região serrana do Estado do Rio de Janeiro: aspectos taxonômicos e ecológicos das espécies. Pesquisas Botânica 44: 41-52.

Smith, L. B. \& Downs, R. J. 1957. Resumo preliminar das Mirsináceas de Santa Catarina. Sellowia 8: 237-252. 
